\title{
Shooting resistance of non-metallic materials
}

\author{
Lesław Kyzioł \\ Polish Naval Academy, \\ L.Kyziol@amw.gdynia.pl
}

\begin{abstract}
This paper presents test results of shooting resistance of non-metallic materials such as ceramics, rubber, glass reinforced plastic (GRP), natural and modified wood. It was demonstrated that GRP samples $16 \mathrm{~mm}$ thick protected with ceramic plates $10 \mathrm{~mm}$ thick can be considered bullet-proof against bullets of $7.62 \mathrm{~mm}$ caliber. And, multi-layer plate with a core of natural or modified wood cannot be taken as a bullet-proof material against $7.62 \mathrm{~mm}$ bullets.
\end{abstract}

Keywords: glass reinforced plastics (GRP), wood-polymer composites, ceramics, rubber, shooting, shooting resistance, ballistic plate

\section{INTRODUCTION}

Polyester laminates can be reinforced with fabrics or mats of glass, carbon or kevlar fibres, and strips or grids of amorphous metals. Such structures applied in shipbuilding are of a small thickness and show low resistance to machine-gun shots of $7.62 \mathrm{~mm}$ caliber, $9.5 \mathrm{~g}$ mass and $830 \mathrm{~m} / \mathrm{s}$ initial velocity [1 $\div 5]$. Therefore to ensure sufficient shooting resistance against 7.62 $\mathrm{mm}$ bullets the GRP laminates should be covered by appropriate shields. As Polish standards in this field are lacking the tests of shooting resistance of shields are carried out in compliance with the requirements of DIN 52290 Standard or EUROPEAN STANDARD CEN, shown in Tab.1.

Tab. 1. Requirements of DIN 52290 Standard and European Standard CEN for shooting tests of shields against $7.62 \mathrm{~mm}$ bullets

\begin{tabular}{|c|c|c|c|c|c|}
\hline Lp & $\begin{array}{c}\text { Kind of } \\
\text { hazard }\end{array}$ & $\begin{array}{c}\text { Kind of } \\
\text { bullet }\end{array}$ & $\begin{array}{c}\text { Bullet } \\
\text { mass } \\
\text { [g] }\end{array}$ & $\begin{array}{c}\text { Bullet } \\
\text { velocity } \\
\mathbf{V}_{\mathbf{5 0}} \text { [m/s] }\end{array}$ & $\begin{array}{c}\text { Shooting } \\
\text { distance } \\
{[\mathbf{m}]}\end{array}$ \\
\hline $\mathbf{1}$ & 4 & $\begin{array}{c}\text { VMS/ } \\
\text { WK }\end{array}$ & $9.45 \pm 0.1$ & $785 \div 795$ & 10 \\
\hline $\mathbf{2}$ & 5 & \multicolumn{6}{|c|}{ VMS/HK } & $9.75 \pm 0.1$ & $800 \div 810$ & 25 \\
\hline \multicolumn{5}{|c|}{$\begin{array}{l}\text { HK- hard-core bullet, WK- soft- steel- core bullet, } V_{50}- \\
\text { velocity at which } 50 \% \text { of bullets are stopped in shield }\end{array}$} \\
\hline
\end{tabular}

New structural and protecting materials are necessary for building and modernizing the ships. To this end shooting tests are carried out in view of application of such materials for building and/or modernizing the locally - armoured ships, as well as military and police land vehicles. Preparation of bullet-proof materials was focused on the condition that the gun-bullets hitting the material's surface could fully dissipate their energy during penetration or even at the end of erosive perforation of shields.

In this paper are presented test results of shooting resistance of selected materials. Behaviour under shooting was tested of GRP laminates covered with ceramic shields and rubber layers, used in building superstructures of naval ships. And, possible application of natural and modified wood as one of ballistic shield layers was investigated. Description of the investigations was presented in detail in [5].

The tests carried out in the Institute of Fundamentals of Construction of Ship Machines, Polish Naval University, Gdynia, were aimed at determining overall ballistic resistance of shields made of various materials. In the subject-matter literature the data on application of non-metallic materials to shields of a higher resistance to bullets and bits, are lacking.

This paper is aimed at experimental determination of ballistic features of samples of $50 \mathrm{~mm}$ diameter formed with a few layers of non-metallic materials under shooting with the use of $7.62 \mathrm{~mm}$ bullets. The samples were installed in a tube fitted with an extensometric force meter, fixed in a ballistic pendulum. The relative effectiveness of the sample was assessed by means of the following formula:

$$
\left(\frac{\text { deflection angle of pendulum }}{\text { deflection angle of pendulum with steel sample }}\right)^{2} \cdot 100 \%
$$

The average deflection angle of pendulum at shooting tests of $12 \mathrm{~mm}$ thick samples amounts to $6.19^{\circ}$ [8].

Capability of absorbing bullet's kinetic energy, revealed by different samples can serve as a measure of their ballistic resistance and the basis to assess their usefulness in designing shields of a higher shooting resistance to bullets and their fragments.

Because of the specific features of the available test stand the force in the tube in which sample is fixed as well as the ballistic pendulum deflection angle in which the tube is fixed, were measured [8] instead of measuring the maximum impact force of bullet and amount of energy absorbed by the sample.

\section{DESCRIPTION OF THE TEST STAND}

The tests were performed in the test stand (Fig. 1) consisted of the ballistic pendulum (6) and two sets of the fixing frames (3), piezo-ceramic detectors (2) replaced after every shot, tube (5) fixed in the pendulum together with extensometric force meter, and the indicator (7) for measuring the pendulum 
deflection angle. After penetrating the first set of two frames the bullet (1) impacts the sample (4) and - after penetrating it - affects the next two piezo-ceramic detectors. The impulse from the first detector triggers the time meter in the oscilloscope (9) which records the instant of bullet's impact in the second detector. This makes it possible to determine the bullet's velocity before hitting the sample. Similarly, the bullet's velocity behind the sample is determined by means of the second set of frames with detectors and the oscilloscope (10). The sample is rested on the tube (5) and tightened with the nut. To ensure a greater overall susceptibility of the sample the pressure exerted on it is so low as to allow its edges to displace against the nut and tube during shooting through the sample. No investigations on possible influence of the sample rigid support in the tube were performed.

The maximum value of the pendulum deflection angle $\varphi$ resulting from a given shot [Tab. 2, column (6)] was read from the indicator's scale. The greater the bullet's impact the greater the pendulum deflection angle (and - in consequence- the amount of energy absorbed by the tested sample).

The bullet's trajectory deviation from the sample axis was equal to about $9 \mathrm{~mm}$ thus the bullet turned up close to the supporting edge of the sample leaving it unpenetrated. Therefore the entire kinetic energy of the bullet was absorbed by the sample and the pendulum inclined up to the angular position $\varphi_{\max }=9^{\circ}$.

As the potential energy of the pendulum in the top position, amounting to :

$$
\mathrm{E}_{\mathrm{pot}}=\operatorname{mgl}(1-\cos \varphi)
$$

where :

$\mathrm{m}-$ mass of the equipped pendulum

$\mathrm{g}$ - gravity acceleration

1 - distance of mass centre from the pivoting axis

$\varphi-$ maximum deflection angle of the pendulum

is equal to the amount of the energy transferred to the pendulum during shooting, the following formula was assumed to be a measure of the effectiveness of particular samples :

$$
\varepsilon=\frac{1-\cos \varphi}{1-\cos 9^{\circ}} \cdot 100 \%=\frac{\sin ^{2} 0.5 \varphi}{\sin ^{2} 0.5 \cdot 9^{\circ}} \cdot 100 \%
$$

For small angles, values of their sines are practically equal to their arguments hence in Tab. 6, col. 9 the following values are introduced :

$$
\varepsilon=\left(\frac{\varphi}{9}\right)^{2} \cdot 100 \%
$$

\section{TESTED LAMINATES AND SHIELDS}

The GRP laminate was tested of $16 \mathrm{~mm}$ and $17 \mathrm{~mm}$ in thickness (marked L16 or L17) applicable to construction of superstructures on special vessels. The GRP laminate additionally reinforced with layers of 1 x $0.032 \mathrm{~mm}$ stripes of canvas fabric of amorphous alloy of $39 \% \mathrm{Fe}, 40 \% \mathrm{Ni}, 1 \%$ $\mathrm{Al}$ and $20 \% \mathrm{~B}$ content, of the tensile strength $\mathrm{R}_{\mathrm{m}}=1560 \mathrm{MPa}$, was marked L18. To stick the metal reinforcement into the laminate, Epidian-5 resin and Z-1 curing agent were used. The GRP laminate additionally reinforced with layers of mat made of the cut amorphous-alloy fibres stuck with the above mentioned resin and curing agent, was marked L22 or L24 depending on its thickness.

To the GRP laminate, D23-E polyester resin was applied as a resinoid bond, and it was also used for the shields smooth plates of the ballistic ceramics $\left(\mathrm{Al}_{2} \mathrm{O}_{3}+\mathrm{SiC}\right)$, having

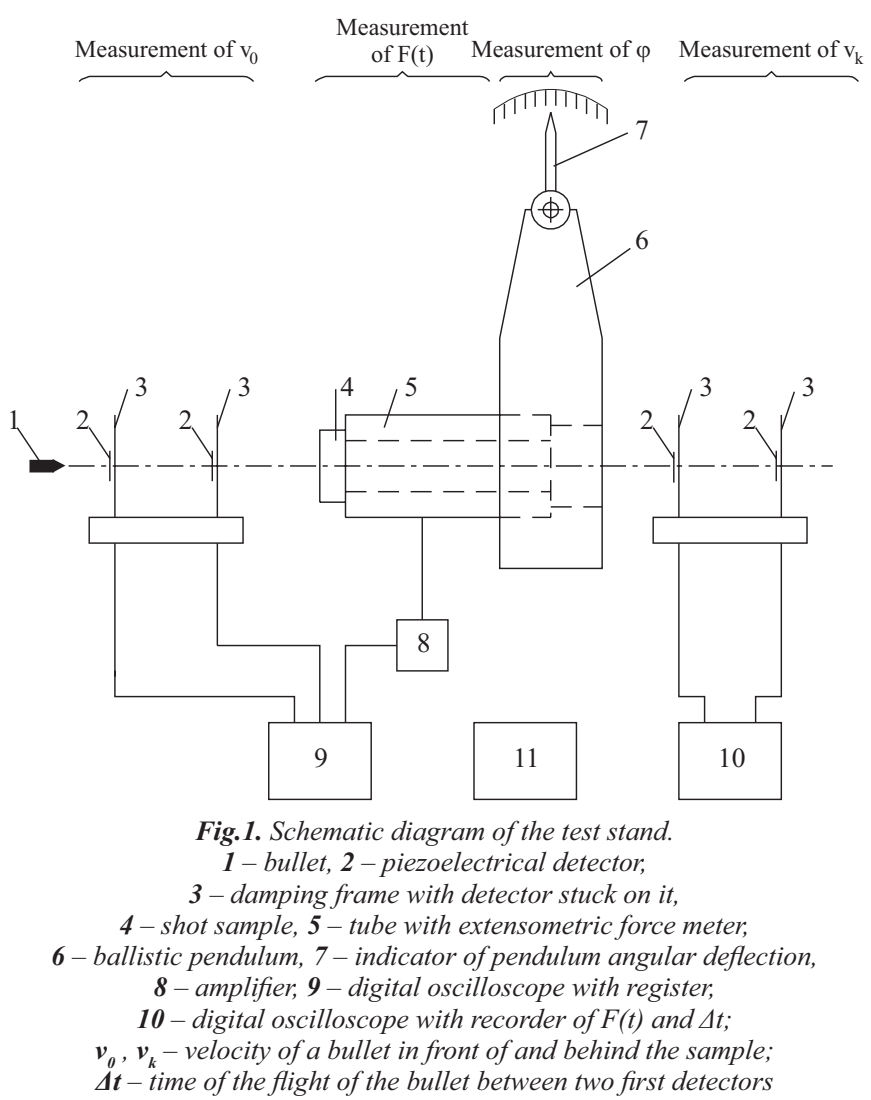

$5 \times 50 \times 50 \mathrm{~mm}$ or $10 \times 50 \times 50 \mathrm{~mm}$ dimensions, and $\mathrm{x}$-relief plates of $5 \times 45 \times 159 \mathrm{~mm}$ and $10 \times 45 \times 159 \mathrm{~mm}$ dimensions, stuck onto the laminate plates. The laminate samples with ceramic shields were marked C5 or C10, depending on shield thickness, or $\mathrm{C} 5 \mathrm{x}$ or $\mathrm{C} 10 \mathrm{x}$, where the shields were made of $\mathrm{x}$-relief ceramic plates. The laminate samples in which $5.5 \mathrm{~mm}$ rubber layer was stuck between the laminate and ceramic shield, were marked /g/, whereas those without rubber layer were marked /-/. Examples of marking the laminate plate samples are shown in Fig. 2 and 3.

a)
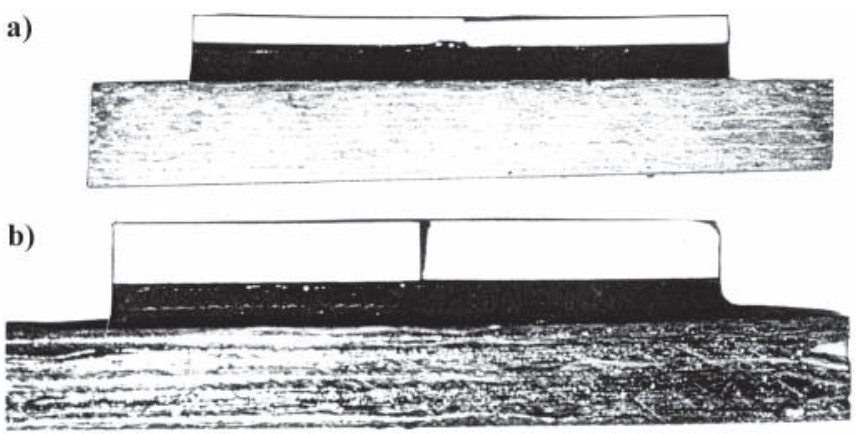

c)

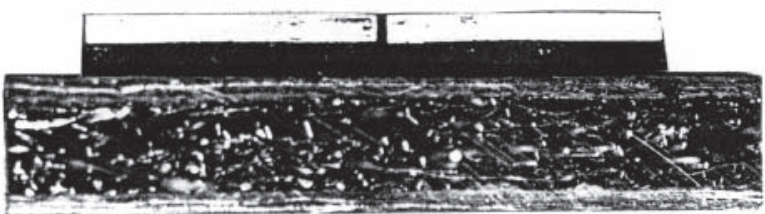

Fig. 2. Examples of CGL ballistic composites (ceramics + rubber + + laminate): a) Al ceramics of $5 \times 50 \times 50 \mathrm{~mm}$ dimensions $+5.5 \mathrm{~mm}$ rubber layer + GRP laminate of $16 \times 140 \times 140 \mathrm{~mm}$ dimensions, marked : C5/g/L16, b) Al ceramics of $10 \times 50 \times 50 \mathrm{~mm}$ dimensions $+5.5 \mathrm{~mm}$ rubber layer $+G R P$ laminate of 16x140x140 mm dimensions, reinforced with amorphous alloy fabric, marked: $\mathrm{C10} / \mathrm{g} / \mathrm{L} 18$, c) Al ceramics of $5 \times 50 \times 50 \mathrm{~mm}$ dimensions $+5.5 \mathrm{~mm}$ rubber layer + GRP laminate of $24 \times 140 \times 140 \mathrm{~mm}$ dimensions, reinforced with amorphous alloy mat, marked : C5/g/L24. 


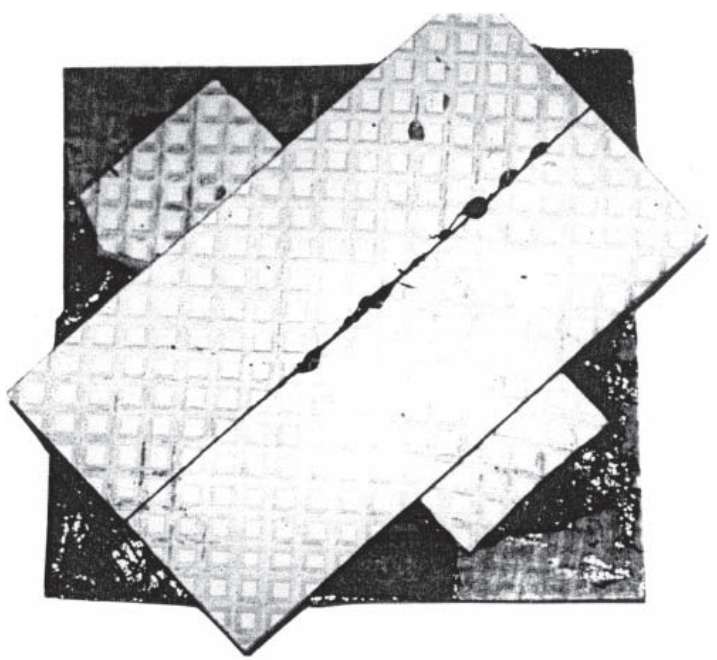

Fig. 3. CGL ballistic composite of the structure : Al x-relief ceramics of $10 \times 45 \times 159 \mathrm{~mm}$ dimensions $+5.5 \mathrm{~mm}$ rubber layer + GRP laminate of $16 \times 140 \times 140 \mathrm{~mm}$ dimensions, marked: C10x/g/L16/.

Nine laminate plate samples fitted with ballistic shields, marked: C5/-/L16, C10/-/L16, C10/g/L16, C5/g/L17, C10/ $\mathrm{g} / \mathrm{L} 17, \mathrm{C} 10 \mathrm{x} / \mathrm{g} / 17, \mathrm{C} 10 / \mathrm{g} / \mathrm{L} 18, \mathrm{C} 5 \mathrm{x} /-/ \mathrm{L} 22$ i C5x/g/L24, were tested.

\section{RESULTS OF SHOOTING RESISTANCE TESTS}

The tests were carried out on the standardized stand for testing ballistic resistance of materials [6]. The $140 \mathrm{~mm} x$ $140 \mathrm{~mm}$ laminate samples were fixed in the head of the tube dynamometer, with ballistic shields heading the shooting direction. The plates were shot with $7.62 \mathrm{~mm}$ bullets of $9.5 \mathrm{~g}$ mass and $830 \mathrm{~m} / \mathrm{s}$ initial velocity, fired from PK rifle from $3 \mathrm{~m}$ distance. The dynamometer recorded course of force changes during bullet's penetration into the sample plate. After shooting image of damage was photographically recorded.

\section{An example of the recorded damage} resulting from bullet's impact :

$\star$ the sample plate $\mathrm{C} 10 / \mathrm{g} / 16$. The course of force due to bullet's impact is shown in Fig. 4. The greatest impact force $\mathrm{F}_{\text {max }}=88.6 \mathrm{kN}$.

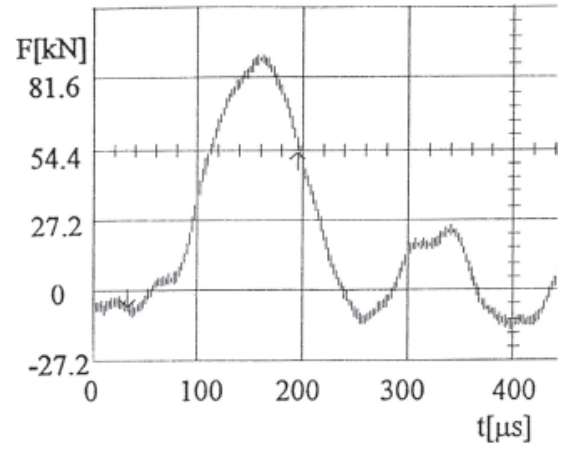

Fig.4. The course of impact force due to $7.62 \mathrm{~mm}$ AP bullet striking with $830 \mathrm{~ms}^{-1}$ velocity into C10/g/16 ballistic plate composed of : Al ceramic plate of $10 \times 50 \times 50 \mathrm{~mm}$ dimensions ++ GRP laminate plate of $16 \times 140 \times 140 \mathrm{~mm}$ dimensions ; $F_{\max }=88.6 \mathrm{kN}$

The bullet damaged the ceramic plate, ballistic erosion of the rubber layer occurred, and small prints of the bullet's size appeared on the struck side of the GDP plate. At the edge of the GRP plate local under-surface shear deformations, and on its rear side shallow delaminations, occurred. (Fig. 5). a)

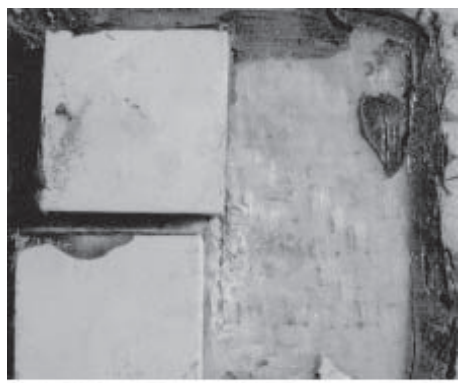

b)

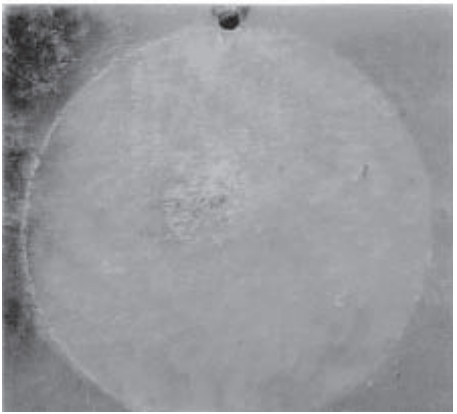

Fig. 5. Effects of shooting the C10/g/16 ballistic composite plate by using $7.62 \mathrm{~mm}$ AP bullet with $830 \mathrm{~ms}^{-1}$ velocity. a) view from the bullet's inlet side, b) view from the GRP rear side.

$\mathrm{F}[\mathrm{kN}]$

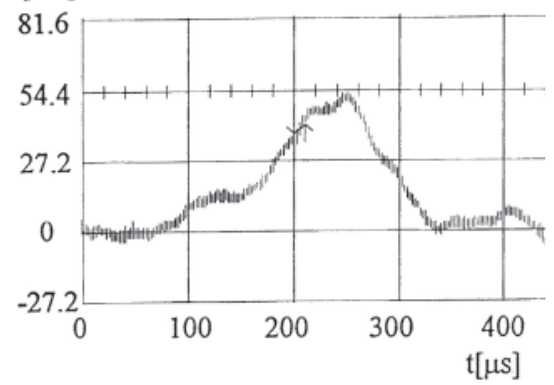

Fig. 6. The course of impact force due to $7.62 \mathrm{~mm}$ AP bullet striking with $830 \mathrm{~ms}^{-1}$ velocity into CGL ballistic plate composed of : Al ceramic relief plate of 5x45x159 mm dimensions + laminate plate reinforced by amorphous metallic mat of 22x140x140 mm dimensions,

$$
\text { marked } C 5 x /-/ L 22 ; F_{\max }=47.5 \mathrm{kN}
$$

$\star$ CGL C5x/-/L22 plates. The course of force due to bullet's impact is shown in Fig. 6.

The greatest impact force $\mathrm{F}_{\max }=54 \mathrm{kN}$.

The bullet penetrated the GRP laminate plate. A partial delamination occurred on the contact surfaces of the amorphous metallic mate with laminate and on the rear side of the laminate (Fig.7).

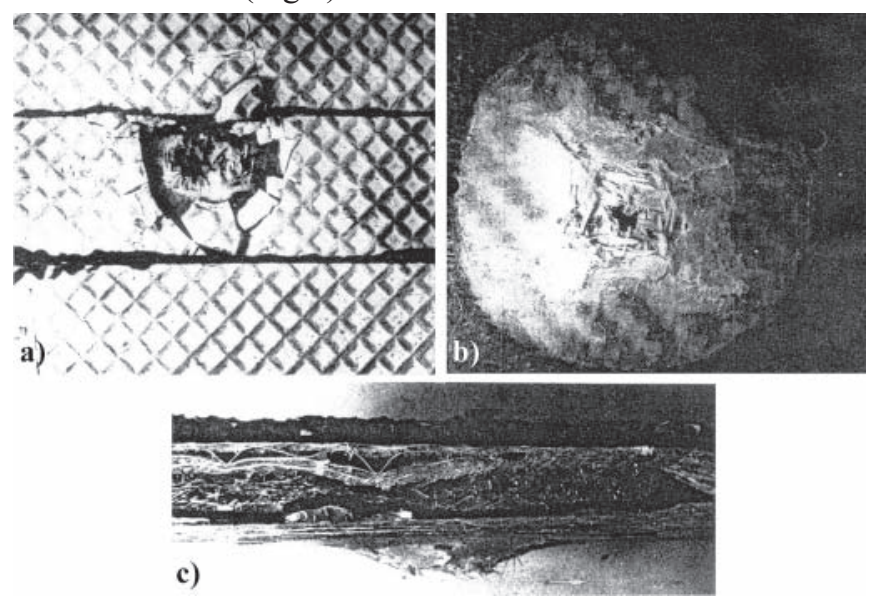

Fig. 7. Effects of shooting the CGL ballistic composite plate by using $7.62 \mathrm{~mm}$ AP bullet with $830 \mathrm{~ms}^{-1}$ velocity, marked C5x/-/L22:a) view from the side of bullet's inlet and outlet, $\boldsymbol{b})$ cross-section of the composite plate c) cross section of the composite 


\section{TESTS OF SAMPLES CONTAINING NATURAL OR MODIFIED WOOD}

Research on modification of wood performed in the Basic Engineering Institute, Polish Naval University, Gdynia, inspired this author to determine shooting resistance of such material applicable to ship structures, assuming that modified wood is used for one of the ballistic plate layers .

In Tab. 2 are presented results of shooting tests of the layered samples in which the inner layer was made of natural or modified wood (16 mm thick) and the outer layers of steel or aluminium disks (6 mm thick). The detailed results of the tests were published in [7]. For the samples under shooting values of the bullet's initial velocity were contained within the range of $790 \div 909[\mathrm{~m} / \mathrm{s}]$.

Tab. 2. Results of ballistic tests. Notation: St - hull structural steel of A grade, Al - AlZn5Mg2CrZr alloy,

$D s$ - pine wood, Dm - modified pine wood, $F s_{\max }$ - maximum compressive force, $F r_{\max }$ - maximum tensile force

\begin{tabular}{|c|c|c|c|c|c|c|c|c|c|c|}
\hline \multirow{3}{*}{$\begin{array}{l}\text { Number } \\
\text { of series }\end{array}$} & \multirow{2}{*}{\multicolumn{3}{|c|}{ Kind sample }} & \multirow{3}{*}{$\begin{array}{l}\text { Number } \\
\text { of sample }\end{array}$} & \multicolumn{2}{|c|}{ Velocity of bullet } & \multirow{2}{*}{$\begin{array}{l}\text { Angle of } \\
\text { pendulum } \\
\text { deflection }\end{array}$} & \multicolumn{2}{|c|}{ Impact force } & \multirow{2}{*}{$\begin{array}{c}\text { Effectivenes } \\
\text { of sample }\end{array}$} \\
\hline & & & & & $\begin{array}{l}\text { Before } \\
\text { sample }\end{array}$ & $\begin{array}{l}\text { Behind } \\
\text { sample }\end{array}$ & & $\max$. & $\min$. & \\
\hline & & & & & $\mathrm{V}_{0}[\mathrm{~m} / \mathrm{s}]$ & $\begin{array}{c}\mathbf{V}_{\mathrm{k}} \\
{[\mathrm{m} / \mathrm{s}]}\end{array}$ & $\varphi[\operatorname{deg}]$ & $\begin{array}{l}\mathrm{Fs}_{\text {max }} \\
{[\mathrm{kN}]}\end{array}$ & $\begin{array}{l}\mathbf{F r}_{\min } \\
{[\mathbf{k N}]}\end{array}$ & $\varepsilon[\%]$ \\
\hline 1 & & 2 & & 3 & 4 & 5 & 6 & 7 & 8 & 9 \\
\hline \multirow{4}{*}{1} & 6 & 16 & 6 & 14.1 & 806 & 370 & 6 & 57 & -21 & 44 \\
\hline & St & Ds & St & 14.2 & 862 & 394 & 6 & 49 & -18 & 44 \\
\hline & & & & 14.3 & 793 & 366 & 5.5 & 52 & -16 & 37 \\
\hline & & & & average & 820 & 377 & 5.8 & 53 & -18 & 42 \\
\hline \multirow{4}{*}{2} & 6 & 16 & 6 & 26.1 & 877 & 434 & 6 & 64 & -29 & 44 \\
\hline & St & $\mathrm{Dm}$ & St & 26.2 & 892 & 374 & 6.5 & 72 & -33 & 52 \\
\hline & & & & 26.3 & 885 & 410 & 6 & 67 & -34 & 44 \\
\hline & & & & average & 885 & 406 & 6.1 & 68 & -32 & 47 \\
\hline \multirow{4}{*}{3} & 6 & 16 & 6 & 18.1 & 851 & 781 & 1.5 & 13 & -5 & 2 \\
\hline & $\mathrm{Al}$ & Ds & $\mathrm{Al}$ & 18.2 & 888 & 745 & 2 & 21 & -6 & 4 \\
\hline & & & & 18.3 & 888 & 765 & 1.5 & 19 & -6 & 2 \\
\hline & & & & average & 876 & 764 & 1.6 & 18 & -6 & 3 \\
\hline \multirow{4}{*}{4} & 6 & 16 & 6 & 30.1 & 869 & 714 & 2.9 & 41 & -19 & 10 \\
\hline & $\mathrm{Al}$ & $\mathrm{Dm}$ & $\mathrm{Al}$ & 30.2 & 909 & 704 & 2.8 & 38 & -17 & 9 \\
\hline & & & & 30.3 & 888 & 666 & 2.2 & 34 & -16 & 5 \\
\hline & & & & average & 887 & 695 & 2.6 & 37 & -17 & 8 \\
\hline \multirow{4}{*}{5} & 6 & 16 & 6 & 22.1 & 869 & 609 & 4 & 34 & -8 & 19 \\
\hline & $\mathrm{Al}$ & Ds & St & 22.2 & 869 & 632 & 4.1 & 30 & -5 & 20 \\
\hline & & & & 22.3 & 869 & 645 & 4.2 & 32 & -6 & 20 \\
\hline & & & & average & 869 & 629 & 4.1 & 32 & -6 & 20 \\
\hline \multirow{4}{*}{6} & 6 & 16 & 6 & 34.1 & 888 & 526 & 4 & 49 & -18 & 19 \\
\hline & $\mathrm{Al}$ & $\mathrm{Dm}$ & St & 34.2 & 869 & 625 & 4 & 50 & -23 & 19 \\
\hline & & & & 34.3 & 869 & 543 & 4.5 & 46 & -15 & 25 \\
\hline & & & & average & 876 & 564 & 4.1 & 48 & -19 & 21 \\
\hline
\end{tabular}


The maximum values of the force in the tube reached from $\mathrm{Fs}_{\max }=68[\mathrm{kN}]$ and $\mathrm{Fr}_{\max }=-32[\mathrm{kN}]$ (steel-modified wood-steel) to $\mathrm{Fs}_{\text {max }}=18[\mathrm{kN}]$ and $\mathrm{Fr}_{\text {max }}=-6[\mathrm{kN}]$ (aluminium-natural woodaluminium). Shooting resistance of the aluminium-modified wood-aluminium layers is comparable to that of aluminiumsand-aluminium and aluminium-glass-aluminium composites. In each case where the outer layers were made of steel and the inner ones of sand, crushed glass or modified wood the lowest shooting resistance was shown by those whose inner layer was made of modified wood. The samples whose inner layer was made of natural wood showed the lowest shooting resistance [7].
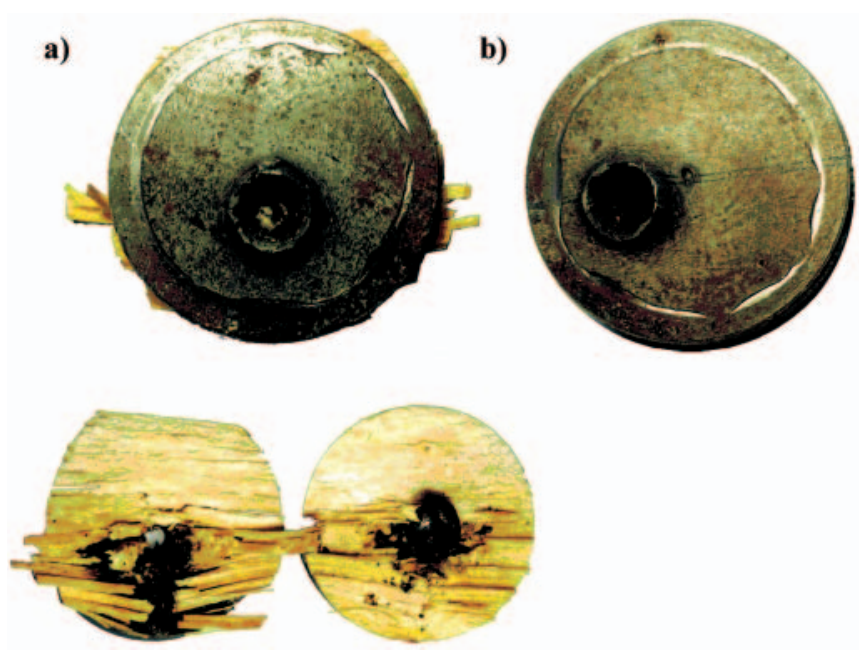

Fig. 8. Example view of the sample having the inner layer made of a) modified wood, b) natural wood

In Fig. 8 the image is shown of the damaged inner layer made of : a) modified wood and b) natural wood. It can be observed that in the case of damaging the inner layer of modified wood (Fig.7a) fragmentation mode prevailed. The resisting inner layer failed. The material fragments observed on the photograph illustrate mode of the damage. The inner layer made of natural wood (Fig. 7b) sustained perforation. The bullet faced no resistance from the side of the layer.

\section{DISCUSSION OF RESULTS}

The obtained results of the shooting tests of GRP laminate plates indicate that the thickness of ballistic shield plays crucial role. It was revealed that the application of $10 \mathrm{~mm}$ ceramic shields made the plates consisted of ceramic shields and GRP laminate resistant to shooting. The bullet's energy was mostly absorbed by a single ceramic plate of $10 \times 50 \times 50$ $\mathrm{mm}$ or $10 \times 45 \times 159 \mathrm{~mm}$ dimensions (Fig.5). In the case when the bullet destroyed a few ceramic plates (Fig.7) they absorbed more impact energy and the bullet penetrated the ceramic shield to a smaller depth. If such plates are thicker they will probably absorb more energy and bullet's impact force will drop faster. Positive results were obtained in the case of application of 5,5 $\mathrm{mm}$ rubber layer between ceramic shield and laminate. The rubber so much absorbed energy of impact of fragments of the bullet and ceramics into laminate that their strikes left only small prints on the laminate surface. It was also showed that the additional reinforcement by means of the layers of metallic fabric or mat introduced to the GRP was not purposeful as it only increased extent of delamination of the laminate, resulting from the bullet's impact. Hence it can be assumed that the GRP laminates additionally reinforced with metallic mat or fabric are less resistant to shooting than the GRP laminate itself. Extent of the delamination of the bullet-penetrated laminate plates was smaller than that in the plates not penetrated by the bullet and it appeared mainly on the rear side of the GRP plates.

To sum up the tests results it can be stated that the highest resistance to shooting with the use of PK rifle and the steelcore bullet of $7.62 \mathrm{~mm}$ caliber, $9.5 \mathrm{~g}$ mass, at its initial velocity of $830 \mathrm{~m} / \mathrm{s}$, was obtained for the laminate plates protected by $\left(\mathrm{Al}_{2} \mathrm{O}_{3}+\mathrm{SiC}\right)$ ballistic ceramic plates of $10 \mathrm{~mm}$ thickness and rubber layer of $5.5 \mathrm{~mm}$ thickness.

\section{CONCLUSIONS}

On the basis of the obtained test results the following conclusions can be offered :

The best protection of the GRP laminate plates of 16-24 $\mathrm{mm}$ in thickness against shooting with the use of $7.62 \mathrm{~mm}$ AP bullets of $9.5 \mathrm{~g}$ mass and $830 \mathrm{~m} / \mathrm{s}$ initial velocity is provided by the $10 \mathrm{~mm}$ plates made of $\left(\mathrm{Al}_{2} \mathrm{O}_{3}+\mathrm{SiC}\right)$ ballistic aluminium ceramics combined with $5.5 \mathrm{~mm}$ rubber layer.

In order to reduce impact energy of bullet fragments striking GRP and ceramics it is purposeful to introduce a rubber layer of about $5 \mathrm{~mm}$ in thickness between the ceramic plates and GRP laminate.

The reinforcing of the GRP with the use of metallic reinforcement is unreasonable as it increases degree of GRP delamination resulting from shooting.

O A modified wood layer is more effective than that of natural wood. It provides a greater absorption of bullet's energy and greater maximum force in the tube.

Destruction process of the intermediate layer made of modified wood due to impact of $7.62 \mathrm{~mm}$ bullet is of entirely different character (fragmentation dominates) than that observed in the case of application of natural wood (perforation dominates).

\section{BIBLIOGRAPHY}

1. Kim S.J., Goo N.S.: Dynamic contact response of laminated composite plates according to the impactors shapes. International Journal of Impact Engineering, vol.65, No 1, 1997.

2. Chun I., Lam K.Y.: Dynamic response of fully clamped laminated composite plates subjected to low velocity impact of a mas. International Journal of Solids and Structures, vol.35, No 11, 1998.

3. Zhu G., Goldsmith W., Dharan C.K.H.: Penetration o laminated kevlar by projectiles. International Journal of Solids and Structures, vol.29, No4, 1992.

4. Goldsmith W., Dharan C.K.H., Chang H.: Quasi-static and ballistic perforation of fiber laminates. International Journal of Solids and Structures, vol.32, No 1, 1995.

5. Zatorski Z.: Resistance to penetration of uniform plates (in Polish). Proc. 7th Domestic Conference on Fracture Mechanics (VII Kraj. Konf. Mechaniki Pękania). Kielce-Cedzyna 2325.09.1999. Scientific Bulletins of Swietokrzyski University of Technology (Zeszyty Naukowe Politechniki Swiętokrzyskiej), Mechanics (Mechanika), vol. 68,Part 2, 1999.

6. J.Fila, Z.Zatorski (authors) : A unified stand for testing ballistic resistance of materials, especially for ship protection and armoured structures (in Polish). Patent UP RP no. 0641 AMW, 1999

7. Kyzioł L.: Tests of ballistic resistance of composites containing modified wood (in Polish). Scientific Bulletins of Polish Naval University (Zeszyty Naukowe AMW), No. 3, Gdynia 2004

8. Kolenda J., Kyzioł L. et al. : Impact and ballistic resistance of a new aluminium alloy and composites containing it (in Polish). Wydz. Mech.-Elektr. Research raport No2 (IPBMO), 2000 